\title{
Rancangan Alat Potong Tahu Tradisional untuk Indutri Rumahan di Kabupaten Nagan Raya
}

\author{
Herdi Susanto*1, Jefri Yanto ${ }^{2}$, Wahyudin ${ }^{3}$ \\ 1,2 Jurusan Teknik Mesin, Fakultas Teknik, Universitas Teuku Umar, Indonesia \\ ${ }^{3}$ Prodi Teknologi Pengelasan Logam, Akademi Komunitas Negeri Aceh Barat, Indonesia \\ *e-mail: herdisusanto@utu.ac.id
}

\begin{abstract}
Abstrak
Proses pengolahan tahu oleh usaha kecil dan industri kecil-menengah di kabupaten Nagan Raya provinsi Aceh masih menggunakan cara tradisional, sehingga menyebabkan hasil produksi perhari masih minim, salah satu kendala dilapangan ditemui bahwa minimnya hasil produksi tahu disebabkan oleh alat kerja untuk memotong tahu masih menggunakan pisau bermata satu (pisau dapur), dari hal tersebut diatas maka pada penelitian ini dilakukan rancangan beberapa model alat untuk memotong tahu yang disesuaikan dengan kebutuhan industri rumahan, tahapan penelitian studi literatur, observasi proses pengolahan tahu pada industri rumahan, perancangan tiga model desain alat dan analisis biaya perunit serta asumsi efesiensi waktu kinerja alat potong tahu. Desain menggunakan software menghasilkan tiga model alat potong tahu yaitu, model I dan II dengan main frame stainless $P=100 \mathrm{~cm}, L=100$ dan $T=5 \mathrm{~cm}$, dan model III main frame stainless $P=100 \mathrm{~cm}, L=8 \mathrm{~cm}$ dan $T=5 \mathrm{~cm}$. Asumsi kinerja alat dari ketiga model desain tersebut dengan pertimbangan biaya produksi dan kecepatan pemotongan, maka dari hasil studi literatur dan observasi proses pembuatan tahu secara tradisional dipilih model III yang lebih sesuai dengan kondisi pekerja industri rumahan di kabupaten Nagan Raya, dengan spesifikasi Main frame stainless Panjang $100 \mathrm{~cm}$ Lebar $1 \mathrm{~cm}$ dan Tinggi $5 \mathrm{~cm}$, kapasitas produksi tahu dengan dua kali potong sebanyak 256 buah dan waktu kecepatan potong 150 detik.
\end{abstract}

Kata kunci-alat potong tahu, industri rumahan, biaya perunit, efesiensi kinerja

\begin{abstract}
Tofu processing by small businesses and small-medium industries in the Nagan Raya district of Aceh province still uses traditional methods, resulting in minimal daily production results, one of the obstacles in the field was found that the lack of tofu production results caused by working tools for cutting tofu still using knives one-eyed (kitchen knife), from the above, in this study, a number of model tools to cut tofu were adapted to suit the needs of the home industry, the stages of research in the study of literature, observation of tofu processing in the home industry, design of three models of tool design and analysis perunit costs and time efficiency assumptions about the performance of the tofu cutting device. Design using software produces three models of tofu cutting tools namely, models I and II with main frame stainless $P$ $=100 \mathrm{~cm}, L=100$ and $T=5 \mathrm{~cm}$, and model III stainless main frame $P=100 \mathrm{~cm}, L=8 \mathrm{~cm}$ and $T=5 \mathrm{~cm},$. Assumption of tool performance from the three design models with consideration of production costs and cutting speed, then from the results of literature studies and observations of the tofu making process traditionally selected model III which is more in line with the conditions of home industry workers in Nagan Raya district, with the specifications of the Long stainless main frame $100 \mathrm{~cm}$ Width $1 \mathrm{~cm}$ and Height $5 \mathrm{~cm}$, tofu production capacity with two pieces of 256 pieces and a cutting speed of 150 seconds.
\end{abstract}


Keywords - tofu cutting tools, home industry, analysis perunit costs, cutting speed

\section{PENDAHULUAN}

$\mathrm{I}_{\mathrm{D}}^{\mathrm{n}}$ ndonesia merupakan salah satu negara produsen tempe dan pasar kedele terbesar di Asia. Dalam proses pengolahan tahu di Indonesia masih bervariasi dan belum adanya standarisasi yang menjadi acuan untuk menghasilkan produk tahu yang berkualitas (Siboro, Siregar, \& Annisa, 2017).

Pengelohan tahu oleh usaha kecil dan industri kecil-menengah (UKM/IKM) sebagian besar masih menggunakan cara pengolahan tradisional. Alat-alat pengolah tahu yang digunakan masih cukup sederhana sehingga hasil produksi yang dihasilkan belum maksimal sesuai dengan kebutuhan pasar. Saat ini banyak kita jumpai para pengusaha industri kecil menolak pesanan yang datang disebabkan oleh kendala teknologi yang dipakai masih begitu sederhana dan jumlah produksi perhari masih sangat minim (Izzhati, 2010).

Nagan raya merupakan salah satu kabupaten di provinsi Aceh yang banyak berkembangnya industri kecil-menengah yang bergerak dibidang industri tahu. Pada tahun 2018 permintaan tahu dari konsumen di pasaran mencapai 907.200 buah/tahunnya di industri rumahan yang terletak di kecamatan Kuala kabupaten Nagan Raya, dan pada tahun 2019 permintaan tahu meningkat mencapai 1.036 .800 buah/tahun (Statistik, 2020). Berdasarkan data ini maka perlu dilakukannya peningkatan produksi tahu dengan memodifikasi alat pemotong tahu di industri tersebut yang mana saat ini masih menggunakan cara tradisional yaitu dengan menggunakan pisau sebagai alat pemotongnya, sehingga pemotongan tahu masih relatif lama dan masih belum bisa memenuhi permintaan konsumen.

Penelitian ini bertujuan untuk merancang beberapa model alat pemotong tahu untuk industri rumahan khususnya yang berada dikawasan kabupaten Nagan Raya Provinsi Aceh, dengan tujuan untuk meningkatkan produksi tahu sehingga dapat memenuhi permintaan konsumen di pasaran.

\section{METODE PENELITIAN}

\subsection{Tempat Dan Waktu Pelaksanaan}

Penelitian ini dilaksanakan dari bulan September - November 2019, Pelaksanaan penelitian dimulai dari tahapan studi literatur, tahapan pengamatan proses pembuatan tahu di lapangan, dan tahapan perancangan dengan tiga model pisau pemotong tahu.

\subsection{Perlengkapan Penelitian}

Adapun perangkat yang digunakan dalam melakukan pelaksanaan mendesain alat pemotong tahu ini menggunakan laptop dan software.

Spesifikasi laptop yang digunakan dipenelitian ini ialah sebagai berikut:

- Operation System : windows 8 Pro

- Processor : AMD A4-3330MX APU with Radeon(tm)

- Memori :2 GB

HD Graphics $2.30 \mathrm{GHz}$

Spesifikasi software yang digunakan dipenelitian ini ialah sebagai berikut:

- Nama : Solidworks 2013

- System Type : 64 Edition SP03

2.3. Observasi Proses Industri Rumahan Pembuatan Tahu

Proses pembuatan tahu pada industri rumahan di kabupaten Nagan Raya dengan tahapan proses sebagai berikut:

a. Perendaman Kacang Kedelai 
Pada proses awal yaitu melakukan proses perendaman kedelai yang bertujuan untuk memperlunak kacang agar lebih mudah dalam memisahkan kulit ari kacang kedelai dan mempermudah pada proses penggilingan sehingga menghasilkan ekstrak yang optimal.

b. Menggiling Kacang Kedelai

Pada tahap ini melakukan penggilingan yang bertujuan agar memperkecil ukuran kacang kedelai sehingga proses pencampuran dapat berlangsung dengan baik. Proses penggilingan dengan menggunakan mesin giling kedelai, seperti ditunjukkan pada Gambar 1.

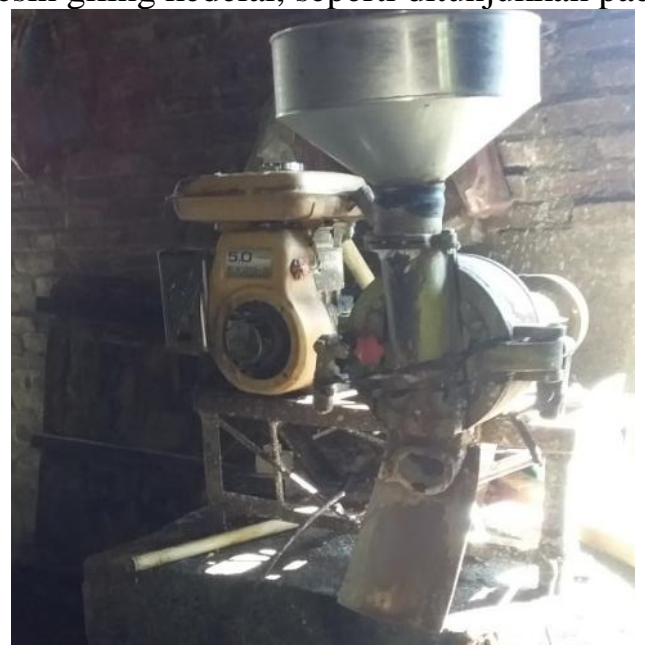

Gambar 1. Mesin penggiling kacang kedelai

c. Merebus Kacang Kedelai

Pada proses ini perebusan biji-bijian kedelai yang telah digiling sebelumnya hingga menjadi seperti bubur kedelai. Kemudian kedelai yang sudah berbentuk bubur tersebut di masukkan kedalam wadah yang berukuran besar yang berisikan air yang mendidih.

d. Penyaringan Pati Kedelai

Pada proses penyaringan adonan bubur kedelai yang telah direbus selama kurang lebih 5 menit, kemudian adonan ini disedot oleh mesin penyedot untuk masuk pada proses pemisahan sari kedelai dari ampas tahunya. Proses penyaringan pati kedelai menggunakan alat pemisah seperti ditunjukkan pada Gambar 2.

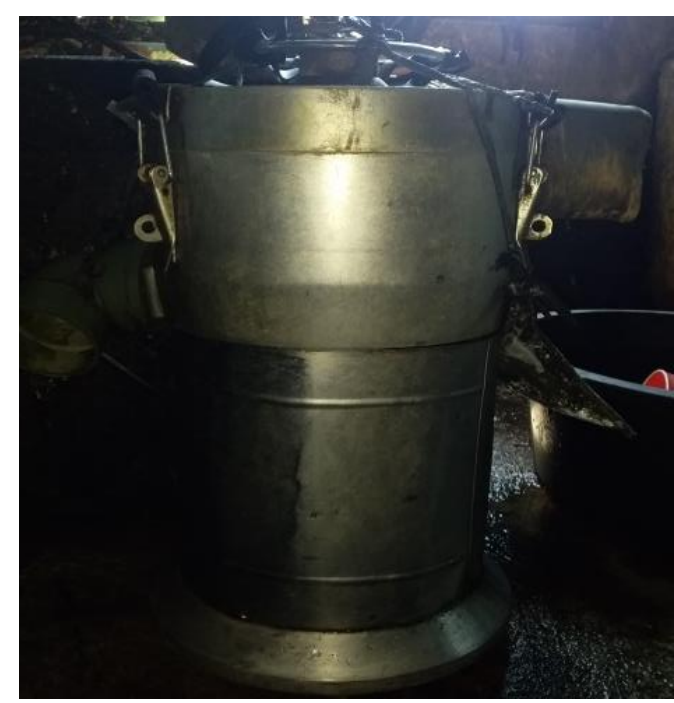

Gambar 2. Alat pemisah pati dan ampas tahu

e. Pencampuran Sari Kedelai dan Ragi 
Pada proses pencampuran, hasil dari proses penyaringan sari kedelai kemudian digumpalkan dengan menambakan bahan yang berupa ragi. Ragi ini merupakan bahan campuran tahu sebelum dimasukkan kecetakan. Wadah yang digunakan sebagai media pencampuran ragi dan sari kedelai ditunjukkan pada Gambar 3.

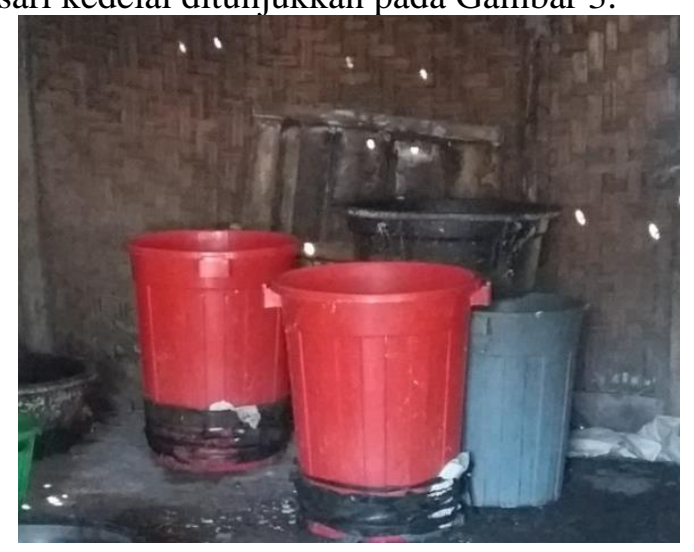

Gambar 3. Wadah pencampuran sari kedelai dan ragi

\section{f. Mencetak Tahu}

Pada tahap ini, dilakukannya proses pengepresan yang bertujuan untuk memadatkan tahu tersebut. Gumpalan dari tahu tersebut dimasukkan kedalam cetakan yang berukuran $100 \mathrm{x}$ $100 \mathrm{~cm}$ yang dilapisi kain saring. Untuk pengepresan, beban yang sering digunakan yaitu air didalam ember. Tujuan dari pengepresan ini agar membuat air keluar sehingga gumpalan tahu menjadi padat. Contoh media cetak tahu yang digunakan oleh industri rumahan di kabupaten Nagan Raya ditunjukkan pada Gambar 4.

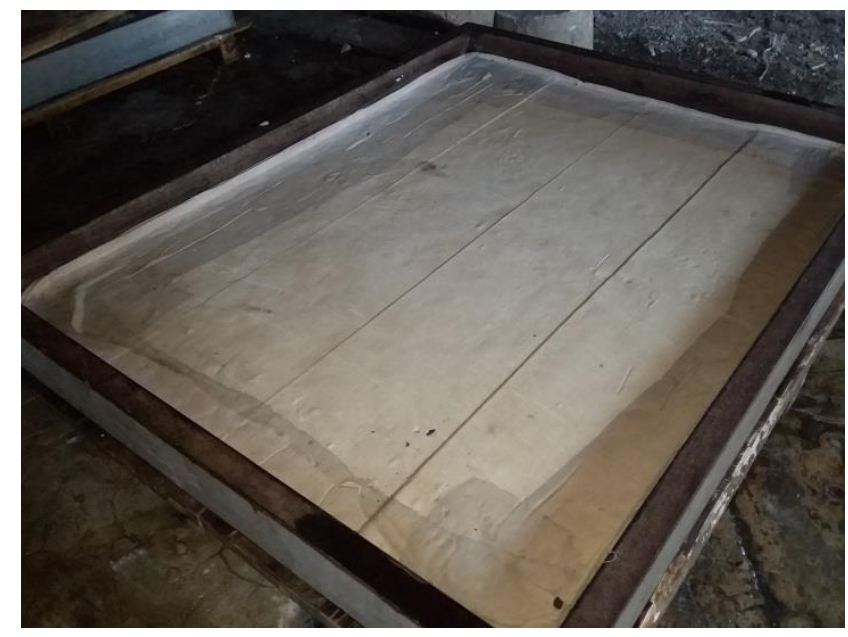

Gambar 4. Cetakan Tahu

g. Pemotongan Tahu

Tahapan terakhir yaitu proses pemotongan yang mana melepas kain saringannya, berikutnya dilakukan proses pengeringan yang bertujuan untuk mengurangi kandungan air dalam tahu agar pada saat pemotongan tidak hancur. Selanjutnya adalah tahu di potongpotong sesuai dengan ukuran yang telah ditentukan. Alat potong tahu yang digunakan selama ini oleh pekerja industri rumahan dikabupaten Nagan Raya yaitu sebilah pisau dapur, seperti ditunjukkan pada Gambar 5. 


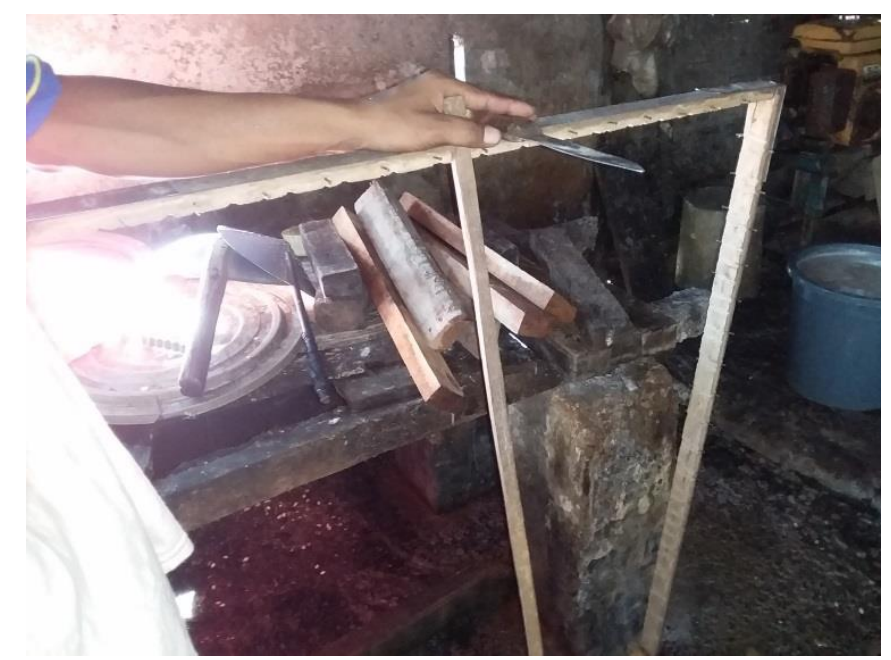

Gambar 5. Alat pemotong tahu tradisional

\subsection{Perancangan Model Alat Pemotong Tahu}

Perancangan model harus berpijak pada suatu kebutuhan setempat dan harus memenuhi peryaratan teknis, persyaratan sosial dan persyaratan ekonomis (H. Susanto, 2018), karena perancangan merupakan perencanaan, penggambaran dan pembuatan sketsa atau pengaturan yang terdapat dari beberapa elemen yang terpisah ke dalam satu kesatuan yang utuh sehingga berfungsi sesuai dengan kebutuhan masyarakat tertentu.

Alat pemotong tahu ini didesain dengan menggunakan Software Solidworks 2013 yang mana bagian-bagian dari komponen alat didesain sesuai dengan spesifikasi dan fungsinya, desain gambar berdasarkan fungsi alat pemotong tahu yang mampu memotong tahu lebih cepat, sehingga diharapkan proses pemotongan menjadi lebih efektif dan efesien. Adapun ketiga rencana model alat potong tahu tersebut, yaitu :

\subsubsection{Desain Pisau Alat Pemotong Model I}

Desain alat pemotong yang direncanakan adalah desain pisau pemotong tahu dengan sakali pengerjaan pada proses pemotongan. Pada desain pisau ini menggunakan bahan stainless steel. Bahan yang digunakan tersebut hanya memiliki tebal $0,5 \mathrm{~mm}$ agar pemotongan lebih mudah.

\subsubsection{Desain Alas Pegangan Alat Pemotong}

Pada desain alas ini dibuat tipis agar pada saat pengoperasian oleh pekerja tidak mempunyai beban yang berlebihan. Pada desain alas pegangan alat pemotong ini menggunakan bahan stainless yang bidang sama besar.

\subsubsection{Desain Penyangga dan Pegangan Alat Pemotong}

Pada desain penyangga dan pegangan alat potong ini menggunakan bahan hollow $2 \times 2$ $\mathrm{cm}$ dengan panjang dari keduanya disesuaikan menurut kenyamanan pengguannya

\subsubsection{Desain Alat Pemotong Model II}

Desain alat pemotong yang direncanakan adalah desain pisau pemotong tahu yang memiliki mata pisau satu arah dengan dua kali proses pengerjaan pemotongan. Pada desain pisau ini menggunakan bahan stainless steel. Bahan yang digunakan tersebut hanya memiliki tebal $0,5 \mathrm{~mm}$ agar pemotongan lebih mudah.

\subsubsection{Desain Alat Pemotong Model III}

Desain alat pemotong yang direncanakan adalah desain pisau pemotong tahu yang memiliki mata pisau satu arah dengan jumlah mata pisau 17 buah dan tahap pengerjaan dua kali proses pemotongan. Pada desain pisau ini menggunakan bahan stainless steel yang memiliki tebal $0,5 \mathrm{~mm}$ dan pegangan berbahan pipa berdiameter $10 \mathrm{~mm}$. Pemilihan bahan tersebut bertujuan agar pemotongan lebih ringan dan mudah. 


\subsection{Analisis Kebutuhan Produksi}

Analisis kebutuhan produksi alat potong tahu dihitung berdasarkan biaya bahan habis pakai dan jasa pekerjaan sesuai dengan harga pasaran yang berlaku di kabupaten Nagan Raya. pemilihan terhadap model alat yang sesuai dengan kebutuhan industri rumahan di nilai dari variable harga produksi dan efesiensi waktu kerja alat.

\subsection{Diagram Alir Penelitian}

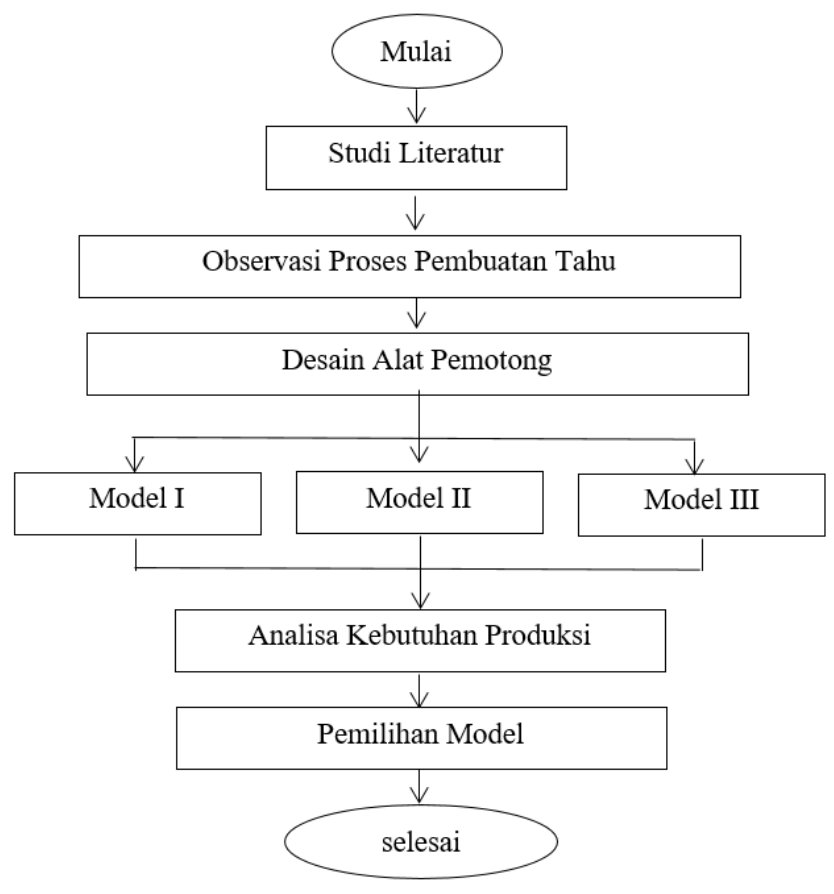

Gambar 6. Diagram Alir Penelitian

\section{HASIL DAN PEMBAHASAN}

3.1. Desain Alat Pemotong Tahu

\subsubsection{Desain Pisau Pemotong Model I}

Alat potong adalah sebuah alat yang digunakan untuk memotong suatu objek, objek yang dimaksud disini adalah tahu. Desain alat pemotong yang direncanakan adalah desain pisau pemotong tahu. Pada desain model I ini menggunakan bahan stainless steel. Adapun ukuran yang akan di desain untuk model I alat pemotong tahu ditunjukkan pada Tabel 1. dan desain alat potong tahu model I ditunjukkan pada Gambar 7.

Tabel 1. Deskripsi komponen desain alat pemotong tahu Model I

\begin{tabular}{|c|l|c|}
\hline No. & \multicolumn{1}{|c|}{ Uraian } & Dimensi $(\mathrm{P} \times \mathrm{L}$ x T) cm \\
\hline 1 & Main frame stainless & $100 \times 100 \times 5$ \\
\hline 2 & Kisi-kisi kolom stainless & $100 \times 6,25 \times 5$ \\
\hline 3 & Kisi-kisi baris stainless & $6,25 \times 100 \times 5$ \\
\hline
\end{tabular}




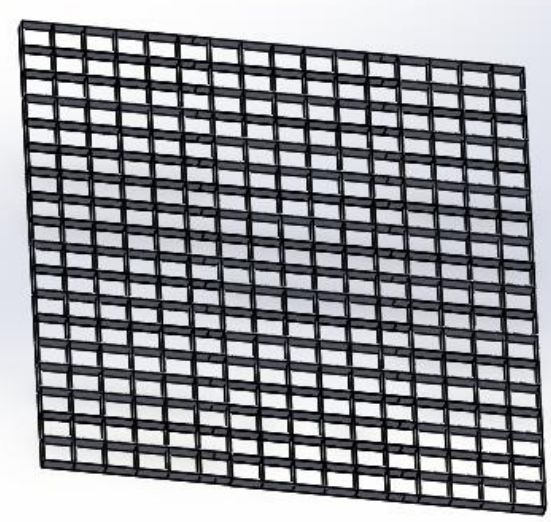

Gambar 7. Pisau pempotong

Alas pegangan alat pemotong adalah sebuah bahan yang berbentuk datar yang tidak terlalu tebal. Pada desain alas ini dibuat tipis agar pada saat pengoperasian oleh pekerja tidak mempunyai beban yang berlebihan. Pada desain alas pegangan alat pemotong ini menggunakan bahan stainless. Adapun ukuran yang akan di desain adalah Panjang $=100 \mathrm{~cm}$ Lebar $=100 \mathrm{~cm}$, ditunjukkan pada Gamhar 8

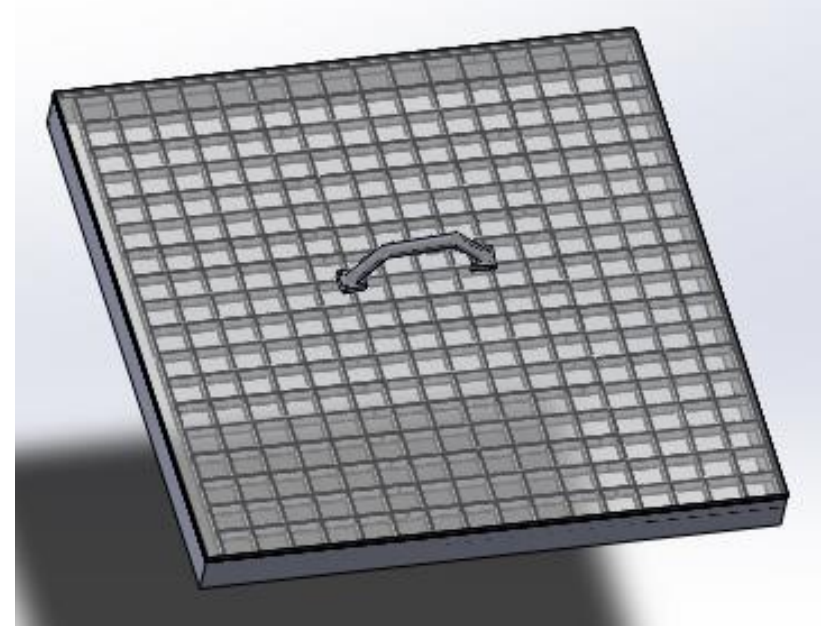

Gambar 8. Alas pegangan alat potong tahu

Penyangga dan pegangan alat pemotong adalah sebuah elemen yang sangat penting pada saat proses pemotongan karena pegangan tersebut mempermudah pada saat pemotongan. Pada desain penyangga dan pegangan alat potong ini menggunakan bahan hollow $2 \times 2 \mathrm{~cm}$. Adapun ukuran yang akan di desain ditunjukkan pada Tabel 2. Dan desain penyangga dan pegangan alat potong tahu ditunjukkan pada Gambar 9.

Tabel 2. Deskripsi komponen desain pegangan alat pemotong tahu

\begin{tabular}{|c|l|c|}
\hline No & \multicolumn{1}{|c|}{ Uraian } & Dimensi \\
\hline 1 & Penyangga & Panjang $=8 \mathrm{~cm}$ \\
\hline 2 & Pegangan & Panjang $=10 \mathrm{~cm}$ \\
\hline
\end{tabular}




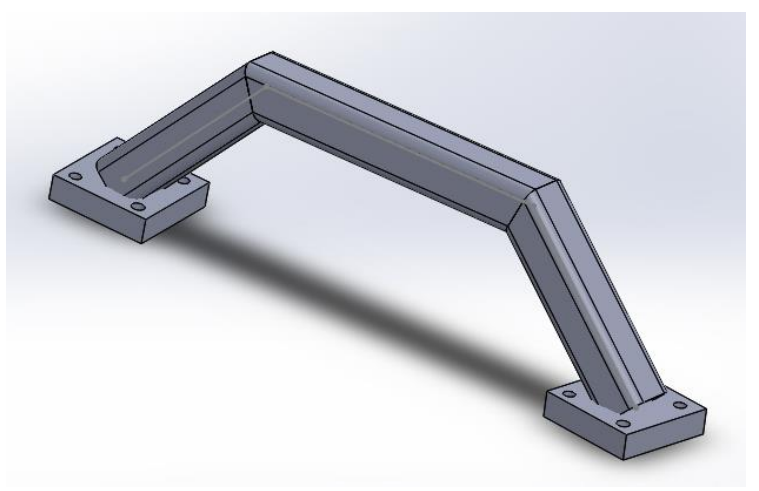

Gambar 9. Penyangga dan pegangan alat potong tahu

\subsubsection{Desain Alat Pemotong Model II}

Desain model II ini menggunakan bahan stainless steel. Adapun ukuran yang akan di desain adalah ditunjukkan pada Tabel 3. dan desain gambar alat pemotong tahu model II ditunjukkan pada Gambar 10

Tabel 3. Deskripsi komponen desain alat pemotong tahu model II

\begin{tabular}{|c|l|c|}
\hline No. & \multicolumn{1}{|c|}{ Uraian } & Dimensi $(\mathrm{P} \times \mathrm{L} \times \mathrm{T}) \mathrm{cm}$ \\
\hline 1 & Main frame stainless & $100 \times 100 \times 5$ \\
\hline 2 & Kisi-kisi baris stainless & $100 \times 6,25 \times 5$ \\
\hline
\end{tabular}

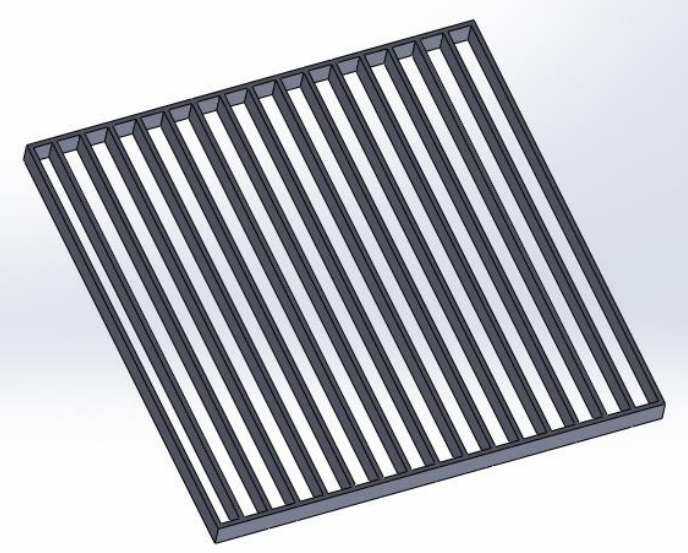

Gambar 10. Alat pemotong tahu model II

\subsubsection{Desain Alat Pemotong Model III}

Desain model III ini menggunakan bahan stainless steel dan pipa. Adapun ukuran yang akan di desain ditunjukkan pada Tabel 4. dan desain gambar alat pemotong tahu model III ditunjukkan pada Gambar 11.

Tabel 4. Deskripsi komponen desain alat pemotong tahu model III

\begin{tabular}{|c|l|c|}
\hline No. & \multicolumn{1}{|c|}{ Uraian } & Dimensi $(\mathrm{P} \times \mathrm{L} \times \mathrm{T}) \mathrm{cm}$ \\
\hline 1 & Main frame stainless & $100 \times 1 \times 5$ \\
\hline 2 & Pegangan dari pipa & $\begin{array}{l}\mathrm{P}=100 \mathrm{~cm} \\
\varnothing=10 \mathrm{~mm}\end{array}$ \\
\hline
\end{tabular}




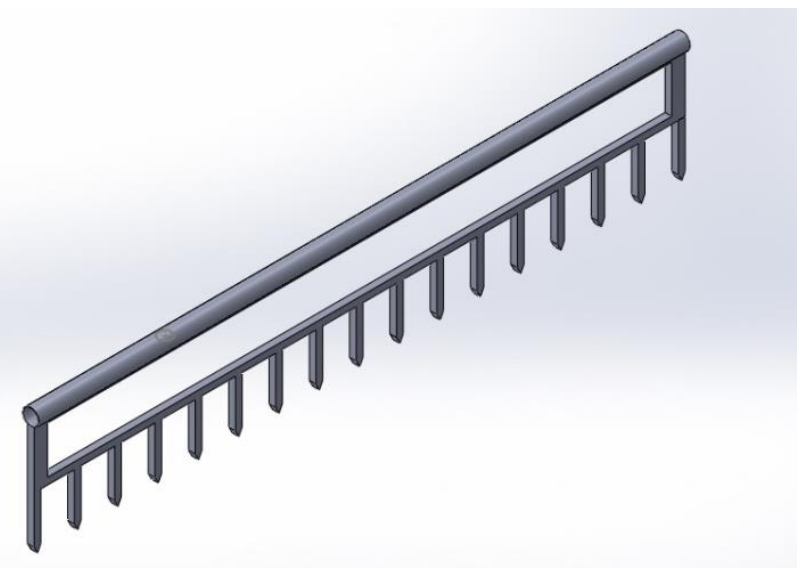

Gambar 11. Alat pemotong tahu model III

\subsection{Analisa Biaya Yang Dibutuhkan}

Berdasarkan data komponen-komponen desain cetakan tahu diatas, maka biaya pembuatan cetakan tahu pada setiap model dihitung sesuai dengan bahan habis pakai dan jasa pekerjaan yang berlaku di kabupaten Nagan Raya, hasil perhitungan ditunjukkan pada Tabel 5., Tabel 6., dan Tabel 7.

Tabel 5. Biaya produksi alat potong tahu model I

\begin{tabular}{|c|l|c|r|r|}
\hline No & \multicolumn{1}{|c|}{ Uraian } & Kuantitas & $\begin{array}{c}\text { Harga Satuan } \\
(\mathrm{Rp})\end{array}$ & \multicolumn{1}{c|}{$\begin{array}{c}\text { Jumlah } \\
(\mathrm{Rp})\end{array}$} \\
\hline 1 & Plat stainless $100 \times 8 \times 5$ & 5 Batang & 15.000 & 75.000 \\
\hline 2 & Biaya pengelasan & 1 Unit & 100.000 & 100.000 \\
\hline 3 & Besi hollow pegangan & 1 Batang & 10.000 & 10.000 \\
\hline 4 & Biaya pengelasan & 1 Unit & 20.000 & 20.000 \\
\hline \multicolumn{4}{|r|}{ Total } & 205.000 \\
\hline
\end{tabular}

Tabel 6. Biaya produksi alat potong tahu model II

\begin{tabular}{|c|l|c|r|r|}
\hline No & \multicolumn{1}{|c|}{ Uraian } & Kuantitas & $\begin{array}{c}\text { Harga Satuan } \\
(\mathrm{Rp})\end{array}$ & $\begin{array}{c}\text { Jumlah } \\
(\mathrm{Rp})\end{array}$ \\
\hline 1 & Plat stainless 100 x 8 x 5 & 3 Batang & 15.000 & 45.000 \\
\hline 2 & Biaya pengelasan & 1 Unit & 50.000 & 50.000 \\
\hline 3 & Besi hollow pegangan & 1 Batang & 10.000 & 10.000 \\
\hline 4 & Biaya pengelasan & 1 Unit & 20.000 & 20.000 \\
\hline \multicolumn{3}{|r|}{ Total } & 125.000 \\
\hline
\end{tabular}

Tabel 7. Biaya produksi alat potong tahu model III

\begin{tabular}{|c|l|c|r|r|}
\hline No & \multicolumn{1}{|c|}{ Uraian } & Kuantitas & $\begin{array}{c}\text { Harga Satuan } \\
(\mathrm{Rp})\end{array}$ & \multicolumn{1}{c|}{$\begin{array}{c}\text { Jumlah } \\
(\mathrm{Rp})\end{array}$} \\
\hline 1 & Plat stainless $100 \times 8 \times 5$ & 1 Batang & 15.000 & 15.000 \\
\hline 2 & Biaya pengelasan & 1 Unit & 20.000 & 20.000 \\
\hline 3 & Besi pipa pegangan & 1 Batang & 5.000 & 5.000 \\
\hline 4 & Biaya pengelasan & 1 Unit & 10.000 & 10.000 \\
\hline \multicolumn{2}{|r|}{ Total } & 50.000 \\
\hline
\end{tabular}

Dari tabel diatas dapat diketahui bahwa biaya pembuatan alat pemotong tahu dari model ke I ini adalah sebesar Rp. 205.000, model ke II sebesar Rp. 125.000, dan model ke III sebesar Rp. 50.000. Biaya ini mempunyai selisih yang berbeda dari model I, model II dan model III yaitu sebesar Rp. 80.000 dan Rp. 75.000. 


\subsection{Efesiensi Waktu}

Setelah desain alat pemotong tahu selesai, maka akan dilakukannya pengasumsian dari kinerja alat tersebut apakah reliabel dalam melaksanakan fungsi dan hasilnya dapat dilihat pada Tabel 8.

Tabel 8. Perbandingan alat pemotong tahu dari ketiga model

\begin{tabular}{|c|c|c|c|}
\hline Model & $\begin{array}{c}\text { Waktu yang dibutuhkan } \\
\text { (detik) }\end{array}$ & Jumlah Potongan & $\begin{array}{c}\text { Jumlah potongan } \\
\text { tahu }\end{array}$ \\
\hline I & 60 & 1 & 256 \\
\hline II & 120 & 2 & 256 \\
\hline III & 150 & 2 & 256 \\
\hline
\end{tabular}

Dari tabel 8 diatas maka dapat disimpulkan bahwa efisiensi waktu yang didapat dari pengasumsian pemotongan tahu dari tiga model alat potong dengan kecepatan waktu pemotongan yang berbeda, desain model I hanya membutuhkan satu kali tekanan ke bidang cetakan tahu untuk menghasilkan potongan tahu dengan ukuran $6,25 \times 6,25 \mathrm{~cm}$, waktu pemotongan ini diasumsikan sekitar 60 detik. Desain model II memerlukan dua kali penekanan dengan arah yang berbeda untuk menghasilkan potongan tahu dan perkiraaan waktu pemotongan sekitar 120 detik. Desain model yang ke-III bekerja dengan cara mengiris bidang permukaan tahu dalam cetakan dengan dua kali irisan pada permukaan tahu dengan arah yang berbeda asumsi waktu yang diperlukan untuk menghasilkan potongan tahu 150 detik, jika dibandingkan dengan menggunakan pisau dapur yang selama ini digunakan oleh pekerja industri rumahan di kabupaten Nagan Raya memerlukan waktu 15 menit (900 detik) untuk menghasilkan potongan tahu berjumlah 256

\subsection{Spesifikasi Desain Alat Pemotong Tahu Terpilih}

Hasil akhir dari desain alat pemotong tahu ini adalah dengan pemilihan model yang sesuai dengan jumlah permintaan konsumen di pasaran dan melihat jumlah biaya saat produksi alat pemotong tahu tersebut adalah desain model III dengan spesifikasi alat ditunjukkan pada Tabel 9.

Tabel 9. Spesifikasi desain alat pemotong tahu model III

\begin{tabular}{|l|l|}
\hline \multicolumn{1}{|c|}{ Parameter } & \multicolumn{1}{c|}{ Keterangan } \\
\hline Main frame stainless & $\begin{array}{l}\mathrm{P}=100 \mathrm{~cm} \\
\emptyset=10 \mathrm{~mm}\end{array}$ \\
\hline Dimensi & 1 Orang \\
\hline Jumlah Operator & 256 buah dua kali pemotongan \\
\hline Kapasitas Desain Alat & Rp. $50.000,-$ \\
\hline Biaya Produksi & 150 detik (dua kali potong) \\
\hline Kecepatan pemotongan & Stainless $1,5 \mathrm{~mm}$ dan pipa $\emptyset 10 \mathrm{~mm}$ \\
\hline Kontruksi Desain & Tahu \\
\hline Jenis Komoditas &
\end{tabular}

\section{KESIMPULAN}

Hasil desain alat pemotong tahu menghasilkan tiga model desain dengan pertimbangan biaya produksi dan kecepatan pemotongan, maka dari hasil studi literatur dan observasi proses pembuatan tahu secara tradisional dipilih model III yang lebih sesuai dengan kondisi pekerja industri rumahan di kabupaten Nagan Raya, dengan spesifikasi Main frame stainless Panjang $100 \mathrm{~cm}$ Lebar $1 \mathrm{~cm}$ dan Tinggi $5 \mathrm{~cm}$, kapasitas produksi tahu dengan dua kali potong sebanyak 256 buah dan waktu kecepatan potong 150 detik 


\section{SARAN}

Untuk mendapatkan hasil yang maksimal, penelitian lebih lanjut dengan pembuatan alat bantu potong tahu dan pengujian langsung diperlukan untuk memaksimalkan pemanfaatan model yang telah di desain.

\section{DAFTAR PUSTAKA}

Siboro, B. A.H, dkk, 2017, Perancangan Alat Pemotong Tahu Untuk Mengurangi Gerak Dengan Metode Motion Time Measurement (MTM)-Motion Time Study (Studi Kasus Pabrik Tahu Pak Joko) . Jurnal Profisiensi, Universitas Riau Kepulauan

Izzhati D. N., 2010, Pengembangan Alat Pemotong Tahu Yang Ergonomis Dengan Menggunakan Metode RULA, Prosiding Seminar Nasional Sains dan Teknologi, Universitas Wahid Hasyim Semarang.

Statistik, B. P. (2020). Tabel Dinamis. Suka Makmue: Badan Pusat Statistik Kabupaten Nagan Raya, Aceh.

H. Susanto, 2018, Desain dan Manufaktur Teknologi Tepat Guna Pedesaan, Bandar Publishing, Banda Aceh 